\section{SUBAORTIC STENOSIS IN THE SPECTRUM OF ATRIOVENTRICULAR SEPTAL DEFECTS}

\section{Solutions may be complex and palliative}

From July 1982 through September 1994, 19 children had operative treatment of subaortic stenosis associated with an atrioventricular septal defect. Specific diagnosis were septum primum defects in 7 , Rastelli type A defects in 6, transitional defects in 4 , inlet ventricular septal defect with malattached chordae in $\mathbf{1}$, and tetralogy of Fallot with Rastelli type $\mathrm{C}$ defect in 1. Twenty-seven operations for subaortic stenosis were performed. Surgical treatment of the outlet lesion was performed at initial atrioventricular septal defect repair in 3 children and in the remaining 16 from 1.2 to 13.1 years (mean 4.9 years, median 3.9 years) after repair. Eighteen of the 19 children had fibrous resection and myectomy for relief of obstruction. Seven children had an associated left atrioventricular valve procedure. One child received an apicoaortic conduit. Seven children $(36.8 \%)$ required 8 reoperations for previously treated subaortic stenosis. Time to the second procedure was 2.8 to 7.4 years (mean 4.9 years). Follow-up is 0.4 to 14.0 years (median 5.6 years). Six-year actuarial freedom from reoperation is $66 \% \pm 15 \%$. The angle between the plane of the outlet septum and the plane of the septal crest was measured in 10 normal hearts $(86.4 \pm 13.7)$ and 10 hearts with atrioventricular septal defects $(22.2 \pm 26.0 ; p<0.01)$. The outfiow tract can be effectively shortened, widened, and the angle increased toward normal by augmenting the left side of the superior bridging leaflet and performing a fibromyectomy. Conclusion: Standard fibromyectomy for subaortic stenosis in children with atrioventricular septal defects leads to a high rate of reoperation. Leaflet augmentation and fibromyectomy may decrease the likelihood of reoperation. (J THORAC CARDIOVASC SuRg 1995; 110:1534-42)

Glen S. Van Arsdell, MD ${ }^{\mathrm{a}}$ (by invitation), William G, Williams, MD, ${ }^{\text {a }}$ Christine Boutin, $\mathrm{MD}^{\mathrm{b}}$ (by invitation), George A. Trusler, MD, ${ }^{\mathrm{a}}$ John G. Coles, MD, ${ }^{\text {Ivan }}$ M. Rebeyka, $\mathrm{MD}^{\mathrm{a}}$ (by invitation), and Robert M. Freedom, MD ${ }^{\mathrm{b}, \mathrm{c}}$ (by invitation), Toronto, Ontario, Canada
$\mathrm{S}_{\mathrm{s}}^{\mathrm{u}}$ ubaortic stenosis associated with atrioventricular septal defects (AVSDs) is a known but uncommon problem. It has been associated with septum primum and Rastelli type $A$ defects more than with Rastelli type $\mathrm{C}$ defects. ${ }^{1,2}$ Piccoli and associates ${ }^{3}$ have estimated the incidence for potential obstruc-

From the Divisions of Cardiovascular Surgery, ${ }^{\mathrm{a}}$ Cardiology, ${ }^{\mathrm{b}}$ and Pathology, ${ }^{\mathrm{c}}$ The Hospital for Sick Children, Toronto, and the Departments of Surgery and Medicine, University of Toronto, Toronto, Ontario, Canada.

Read at the Seventy-fifth Annual Meeting of The American Association for Thoracic Surgery, Boston, Mass., April 23-26, 1995.

Address for reprints: Robert Freedom, MD, Cardiology, Hospital for Sick Children, 555 University Ave., Toronto, Ontario, Canada M5G 1X8.

Copyright (C) 1995 by Mosby-Year Book, Inc.

$0022-5223 / 95 \$ 5.00+0 \quad \mathbf{1 2 / 6 / 6 7 8 6 0}$ tion in pathologic specimens of AVSDs to be $70 \%$; however, the actual incidence of unequivocal obstruction in that series was only $7 \%$. Others have reported a prevalence of $3 \%$ to $4.5 \%$. 1,4

This report reviews the anatomic causes of obstruction in 19 children with AVSDs and discusses treatment options, results, complications, and surgical methods of management that are tailored to the obstructive anatomy of the individual patients.

\section{Patients and methods}

A Department of Cardiovascular Surgery computer database search from July 1982 through September 1994 elicited 19 patients with AVSDs who received operative treatment for subaortic stenosis. During that same period 528 children had repair of AVSDs. Operative reports, cardiology and cardiac surgery files, echocardiography reports, and cardiac catheterization reports were reviewed on all patients to determine mechanisms of obstruction 
and recurrence of subaortic stenosis. Additionally, 32 cineangiograms on 17 patients were reviewed (R.M.F. and G.S.V.). Thirteen of these were diagnostic catheterizations for AVSDs, 1 was performed after AVSD repair, and 18 were diagnostic procedures for subaortic stenosis. Sixty-three echocardiography tapes, of which 26 were obtained before surgical treatment of subaortic stenosis and 37 after treatment, were reviewed (C.B. and G.S.V.). Children with unbalanced AVSDs that precluded biventricular repair were excluded from this series.

Twenty-seven operations for subaortic stenosis were performed on these 19 children, all but two being performed at the Hospital for Sick Children, Toronto. Specific diagnoses included 10 AVSDs with atrioventricular (AV) valve chordal attachments to the crest of the septum; 6 involved an unrestrictive ventricular septal defect (VSD) (Rastelli type A) and 4 a restrictive (transitional) VSD. Seven patients had a septum primum defect, 1 patient an inlet VSD and malattached chordae, and 1 patient had tetralogy of Fallot and a Rastelli type C defect. Three patients had previous repair of coarctation, ${ }^{5}$ 2 patients had previous pulmonary artery banding, and 1 had a Blalock-Taussig shunt. Nine patients had Down syndrome. Age at initial subaortic resection was 17 months to 13 years (median 4 years).

Eleven of the 19 patients had a VSD component to their defect. Initial repair of the VSD had been accomplished with a one-patch technique in 6 children, a two-patch technique in 4 , and direct suture closure of a small VSD in 2.

Operative procedure. Indications for operative repair of subaortic stenosis were identification of subaortic stenosis before the initial AVSD repair in 3 patients or anatomic and hemodynamic obstruction after AVSD repair, defined by echocardiography, cardiac catheterization, or both, in 16 patients. Associated gradients were as follows: a peak-to-peak gradient greater than or equal to $40 \mathrm{~mm} \mathrm{Hg}$, a Doppler mean gradient greater than $40 \mathrm{~mm}$ $\mathrm{Hg}$, or a Doppler peak gradient greater than or equal to $50 \mathrm{~mm} \mathrm{Hg}$. Surgical treatment of the outlet lesion was performed at initial AVSD repair in 3 children and from 1.2 to 13.1 years (mean 4.9, median 3.9) after AVSD repair in the remaining 16 .

Abnormalities identified at the initial operation for subaortic stenosis included isolated fibromuscular stenosis in 9 patients, combined fibromuscular stenosis and left AV valve abnormalities in 6 , fibromuscular stenosis and papillary muscle obstruction in 3 , and tunnel stenosis in 1 patient. The left AV valve abnormalities identified were accessory tissue tags, accessory chordae, abnormal leaflet bulging, and in 1 patient essential chordal structures.

Initial operation for subaortic stenosis. Repair was accomplished with cardiopulmonary bypass and moderate hypothermia. Antegrade blood or crystalloid cardioplegia was given for myocardial protection. Cannulation was performed in the ascending aorta and right atrium unless a concomitant left $\mathrm{AV}$ valve procedure was necessary, in which case bicaval cannulation was used.

Eighteen of the 19 children had fibrous resection and myectomy for relief of obstruction. Nine patients had this resection as an isolated procedure. Three had simultaneous repair of the AVSD. One patient had replacement
Table I. Patients requiring second operation for subaortic stenosis

\begin{tabular}{lcc}
\hline \multicolumn{1}{c}{ Diagnosis } & $\begin{array}{c}\text { No. of } \\
\text { Total } \\
\text { patients }\end{array}$ & $\begin{array}{c}\text { reoperations for } \\
\text { subaortic stenosis }\end{array}$ \\
\hline $\begin{array}{l}\text { Septum primum defect } \\
\text { Chordal attachment to septal crest } \\
\quad \text { transitional or type A Rastelli) }\end{array}$ & 10 & 2 \\
Type C with tetralogy of Fallot & 1 & 6 \\
Inlet VSD and malattached chordae & 1 & 0 \\
\hline
\end{tabular}

of the left $A V$ valve because essential chordae caused left ventricular outflow tract (LVOT) obstruction. One patient each had simultaneous excision of a minor papillary muscle to the right-sided AV valve obstructing the LVOT, completion of cleft closure, completion of cleft closure with annuloplasty, and thinning of an obstructing anterolateral papillary muscle. One child had pericardial patch enlargement of the superior left AV valve leaflet, as has been previously described., 6-8 Resection was accomplished by way of an aortic root incision except in 2 patients, in whom fibromyectomy was performed through the left AV valve orifice at initial repair of the AVSD. The patient who did not have fibromuscular resection received an apicoaortic conduit.

Reoperation for subaortic stenosis. Seven children (36.8\%) required 8 reoperations for previously treated subaortic stenosis (Table I). Two were treated at reoperation by fibromyectomy alone. Two were treated by a radical fibromyectomy and creation of an infundibular VSD along with patch repair of the surgically created VSD from the right ventricular side (modified Konno operation). ${ }^{9}$ One patient had fibromyectomy with left AV valve replacement for complex obstructing valve apparatus and another child had fibromyectomy with papillary muscle thinning. The child treated by an apicoaortic conduit required conduit replacement 6 years later. Nine years after the initial conduit insertion, successful conversion to antegrade flow was accomplished by subaortic fibromuscular resection, removal of accessory chordae and tissue of the left AV valve, and conduit excision. Completion of left AV valve cleft closure was also required. This child's peak-to-peak left ventricular-aortic gradient was $19 \mathrm{~mm} \mathrm{Hg}$ after conversion to antegrade flow. In 2 of the 3 patients who had subaortic resection at initial AVSD repair, the obstruction recurred. Length of time to a second procedure in these 7 children after initial resection was 2.8 to 7.4 years (mean 4.9 years). By actuarial analysis, freedom from reoperation for subaortic stenosis at 6 years is $66 \% \pm 15 \%$ (Fig. 1). ${ }^{10}$

Follow-up. Two children had postoperative cardiac complications. One patient requiring left AV valve replacement had an emergency reoperation and replacement of the valve because of a sticking leaflet 6 days after the initial insertion. In a second patient a left ventricular outlet aneurysm developed after fibromyectomy. Repair is pending. Clinical follow-up from operative treatment of subaortic stenosis ranged from 0.4 to 14.0 years (mean 5.4 years, median 5.6 years). Echocardiographic follow-up was 2 weeks to 13.3 years (mean 5.2 years, median 5.5 


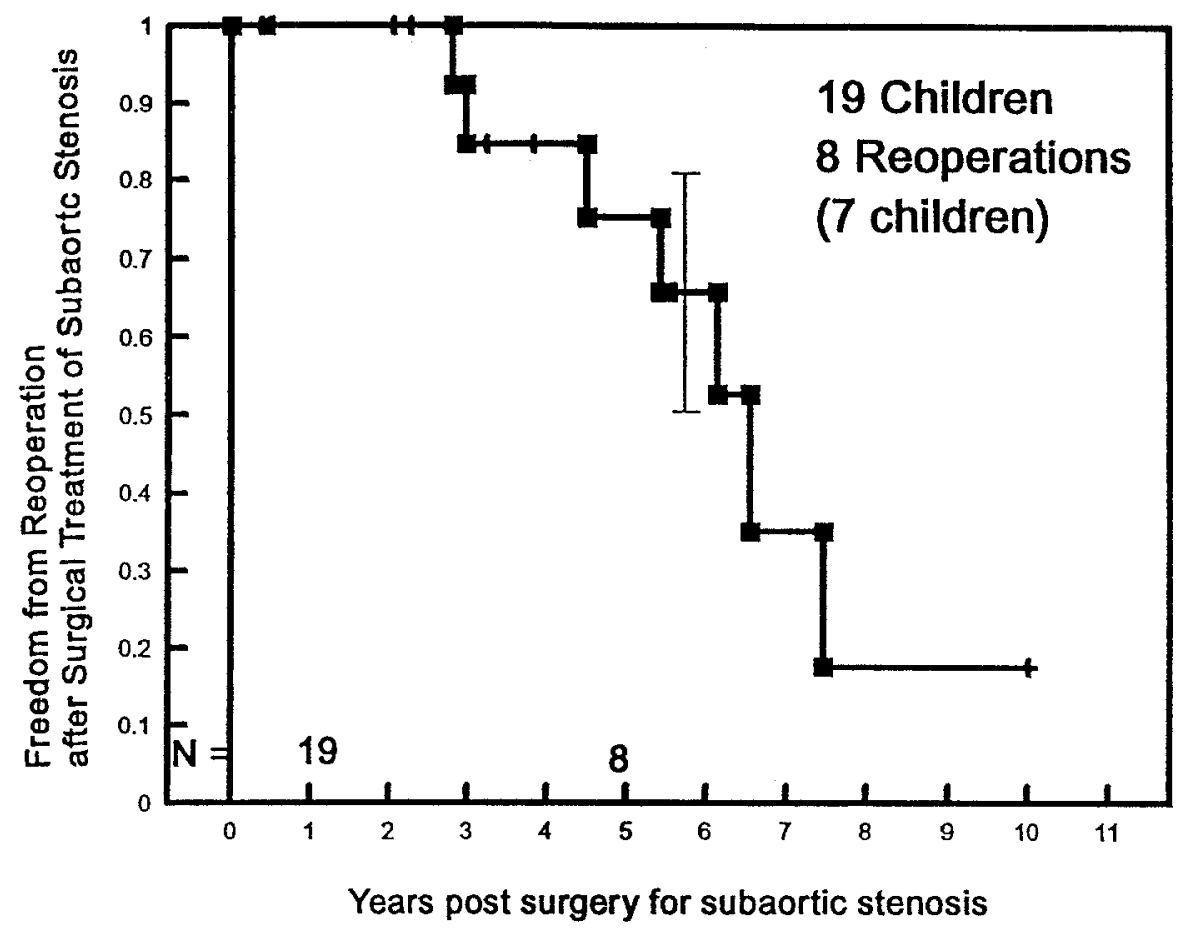

Fig. 1. Actuarial freedom from reoperation in patients with subaortic stenosis plus AVSD.

years). Mean gradients by Doppler assessment were trivial in 14 patients ( 0 to $10 \mathrm{~mm} \mathrm{Hg}$ ). Three patients had a mild gradient ( 11 to $20 \mathrm{~mm} \mathrm{Hg}$ ) and 2 had moderate gradients (21 to $50 \mathrm{~mm} \mathrm{Hg}$ ). Sixteen of the 19 patients had mild aortic insufficiency. The remaining 3 had trivial or no aortic insufficiency. Fourteen had mild left AV valve insufficiency, 2 moderate insufficiency, and 1 patient no left AV valve insufficiency. Two patients had appropriately functioning mechanical left AV valve prostheses. No patient was lost to follow-up.

Pathologic specimens. Ten normal and 10 AVSD pathology specimens with either transitional or septum primum type defects were examined to measure the angle of the plane of the crest of the ventricular septum as compared with the plane of the outlet septum (Fig. 2). The normal hearts exhibited an angle of 69 to 110 degrees (mean 86.4 degrees, standard deviation \pm 13.7 degrees). The angle of the planes measured in the AVSD specimens varied from -8 degrees to 71 degrees (mean 22.2 degrees, standard deviation \pm 26.0 degrees) (Student's $t$ test, using unequal variance, $p<0.01)$. The smaller angles corresponded with the relative increase in the "scooped out" crest of the ventricular septum.

\section{Discussion}

Surgical management of the anterior portion of the VSD at initial repair can influence the size of the LVOT and potential for subaortic stenosis. Suture closure of a small anterior VSD binds the leaflet to the "scooped out" ventricular crest and narrows the LVOT. Conversely, a large anterior component to the VSD patch enlarges the outflow tract and potentially decreases the possibility of subaortic stenosis. Appropriate initial AVSD repair may lessen the prevalence of subsequent subaortic stenosis.

Mechanisms of subaortic obstruction in patients with AVSDs include discrete fibrous stenosis, tunnel stenosis, accessory left AV valve tissue and chordae, essential left AV valve tissue and apparatus, aneurysm of the mitral valve, abnormal papillary muscles, anteroseptal twist, malaligned aorta over the septum, hypertrophic muscle, and mitral prosthesis. ${ }^{1-3,5,11-17}$ The predominant anatomic abnormality of acute hemodynamic importance in this series was an acquired discrete fibrous subaortic ridge. Whereas 6 of 19 patients had chordae or tissue tags from the left AV valve, 1 had abnormal papillary muscle in the LVOT, and 1 had tunnel stenosis, each patient had fibrous subaortic stenosis with a component of excessive muscle, regardless of other abnormalities. Although it was not the underlying cause, at operation this fibrous and muscular tissue was thought to be the immediate source of obstruction in 16 of 19 patients. 

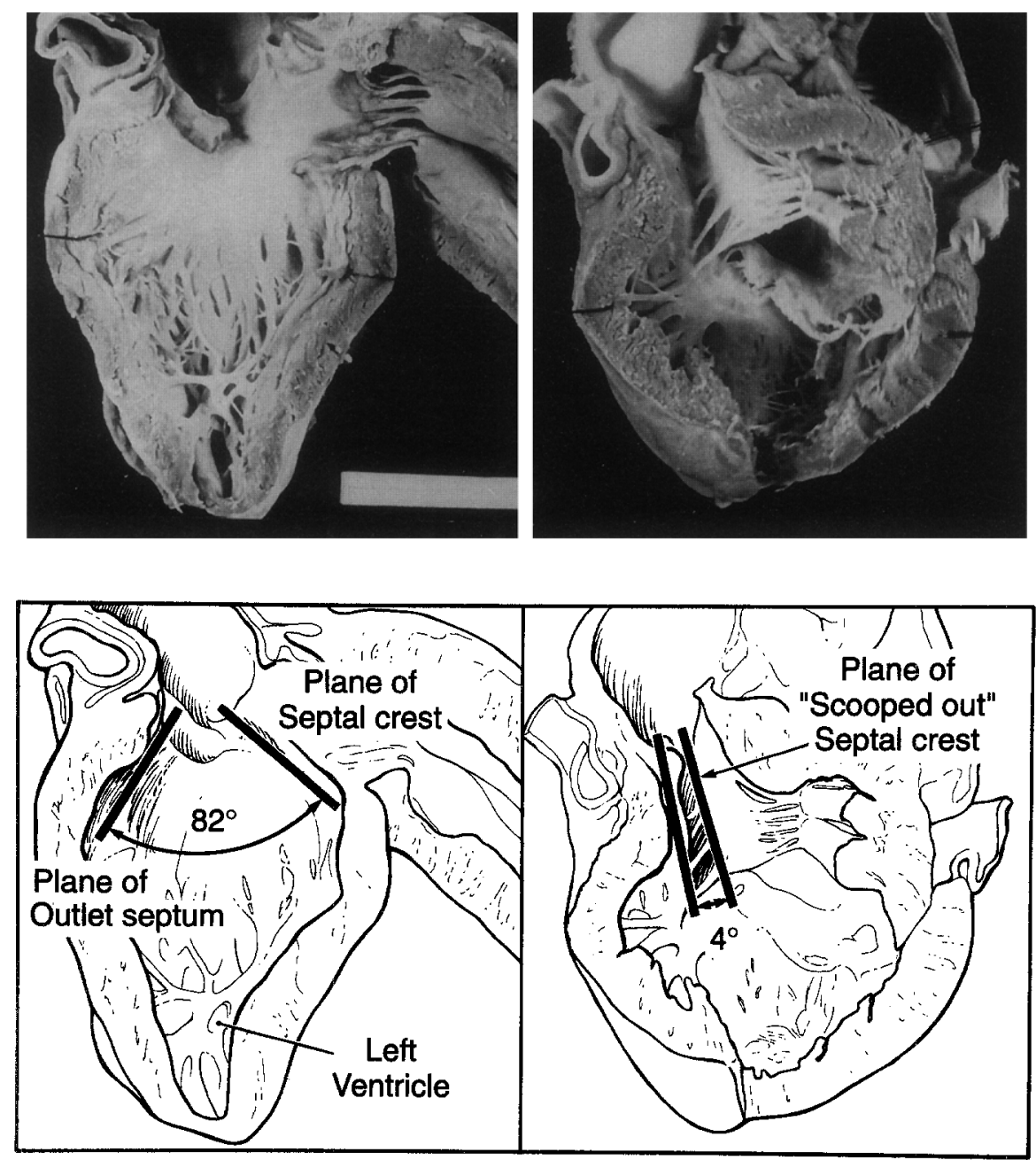

Fig. 2. Left, Wide angle between the plane of the outlet septum and the crest of the septum (outflow angle) in a normal heart. Right, Narrow angle in a heart with AVSD.

Recurrence rate of subaortic stenosis after operative treatment in reports not specifically related to AVSD is $15 \%$ to $17 \% \%^{18,19}$ but may be time dependent. The rate of reoperation was high in children in this series treated by fibromyectomy without leaflet augmentation, left AV valve replacement, or creation of an infundibular VSD and subsequent patching. Excluding those patients whose follow-up is less than 1 year, the reoperation rate was 50\% (6/12). This result has led us to believe that standard subaortic resection with myectomy is palliative and that additional enlargement of the LVOT is necessary.

As pointed out by Jue and Edwards, ${ }^{20}$ as well as Piccoli and associates, ${ }^{3}$ the morphologic features of
AVSD promote actual or potential subaortic stenosis. In discrete or fibromuscular obstruction not associated with AVSD, the cause of this lesion can be a somewhat narrowed and elongated LVOT. ${ }^{21}$ In AVSD the LVOT is narrowed and elongated because of increased aortic and left AV valve separation, ${ }^{6,22}$ as well as a "scooped out" septal crest. This situation provides the basis for development of fibrous subaortic stenosis. Performing a standard fibromyectomy relieves obstruction over the short term, but the topography is not significantly altered. We believe the resulting anatomic setup is conducive to recurrence.

Lappen and associates ${ }^{8}$ in 1983 described augmentation of the superior bridging leaflet of the left 

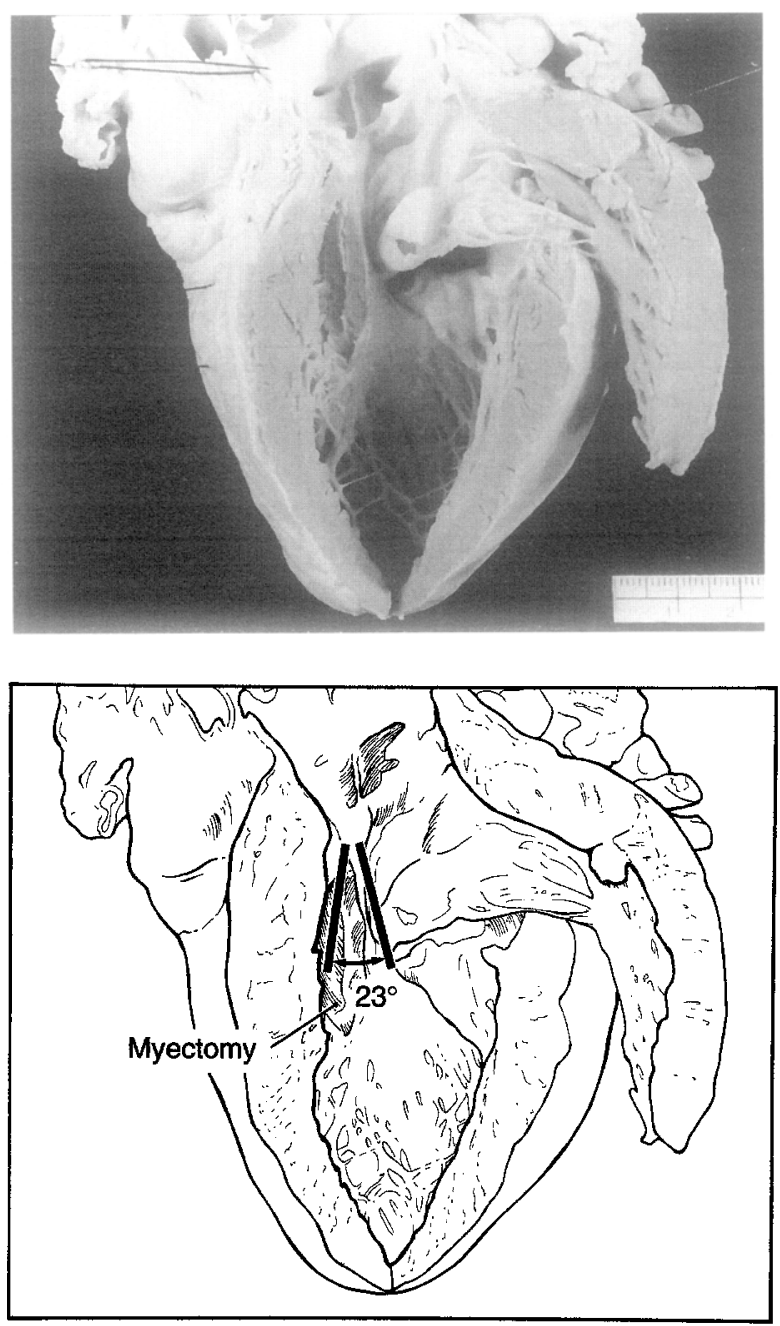

Fig. 3. Mild enlargement of the outflow angle with myectomy. The LVOT remains narrow and long.

$A V$ valve as a means of relieving obstruction caused by attachment of the leaflet to the "scooped out" crest of the ventricular septum. Recently (1994) Starr and Hovaguimian ${ }^{7}$ reported a successful case of such a repair and further detailed the concept of lifting the superior leaflet. Chang and Becker ${ }^{23}$ advocated converting a Rastelli type A defect to a type $C$ lesion by detaching the greater part of the tightly bound superior leaffet and then patching the enlarged VSD and repairing the atrial component.

Of the described repairs, leaflet augmentation and conversion of the defect to a Rastelli type C lesion are the only methods that address the ventricular inlet abnormality, which is the cause of the elongated LVOT. The normal LVOT has an angle of nearly 90 degrees between the plane of the outlet
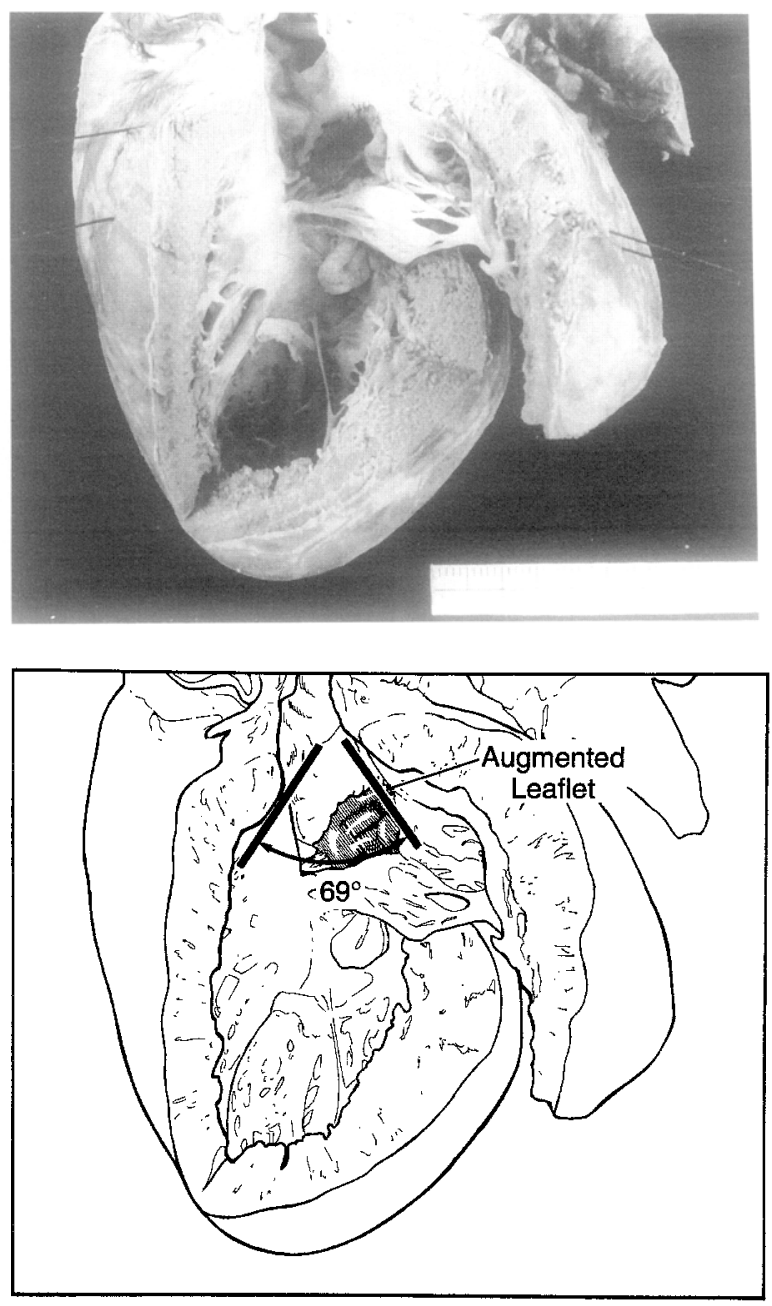

Fig. 4. Left $A V$ valve leaflet augmentation and lifting of the superior bridging leaflet. The superior bridging leaflet is detached from the anterior portion of the septal crest extending to the region just to the left of the LVOT. The increased mitral aortic separation is excised. A pericardial patch augments the leaflet and closes the VSD (if present).

septum and the plane of crest of the ventricular septum. This angle varies in AVSD, but in the 10 specimens measured it averaged 22 degrees. This angle represents the angle of the LVOT in those specimens having leaflet or chordal attachments to the crest of the septum. Performing subaortic resection and myectomy alone in these cases enlarges the LVOT but does little to change this angle (Fig. 3). The LVOT remains long and narrow, leaving the hemodynamic setting that led to the initial subaortic fibrous stenosis. Augmentation of the superior bridging leaflet alters the effective plane of the crest 

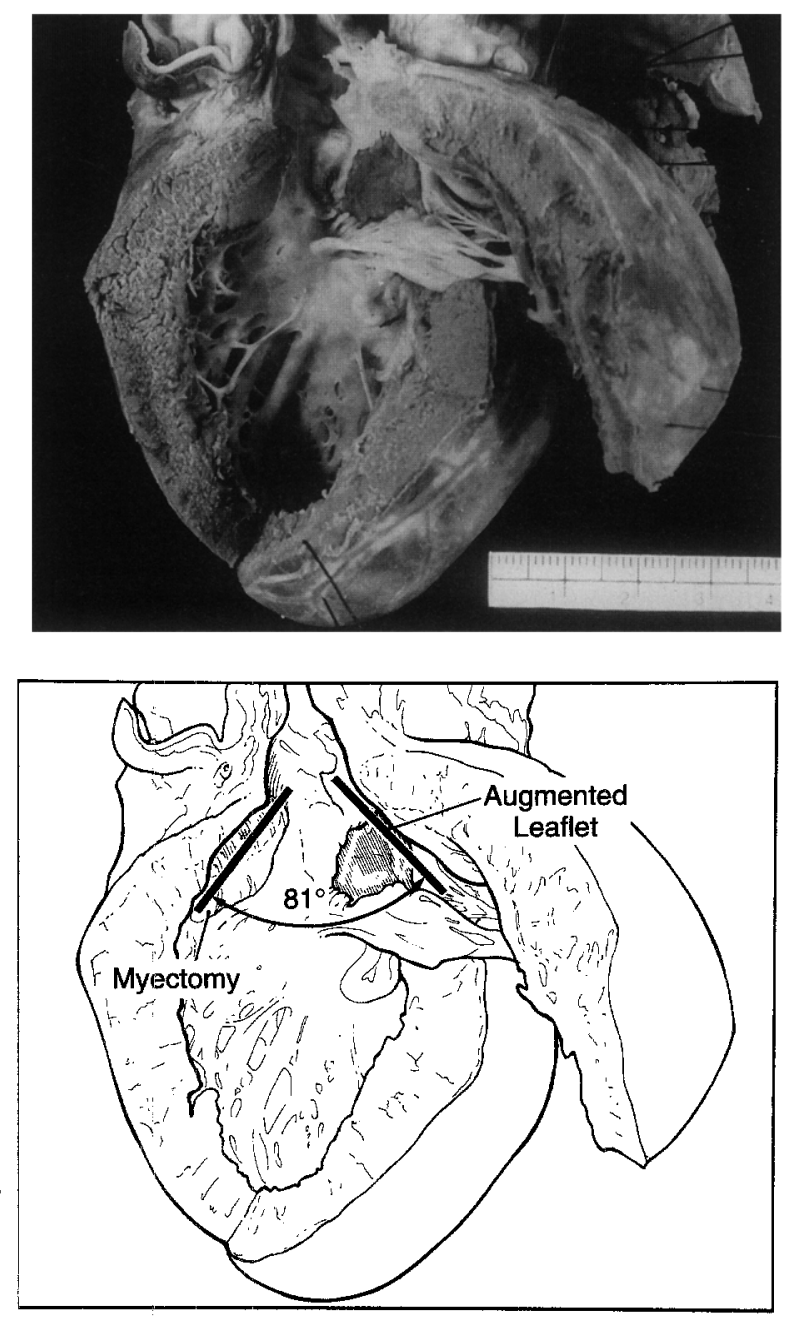

Fig. 5. Addition of myectomy to leaflet augmentation widens the outflow angle to near normal. This effectively shortens and widens the LVOT.

of the septum because of leaflet billowing during systole (Fig. 4). This correction of the inlet defect widens and shortens the LVOT and thereby enlarges the outflow angle. Because of the increased left $\mathrm{AV}$ valve and aortic separation, a myectomy is necessary and serves to further widen the LVOT (Fig. 5). Creation of an infundibular VSD and subsequent patching from the right ventricular side also enlarges the outflow angle but does not alter the inlet anatomy (Fig. 6). Patients with Rastelli type $\mathrm{C}$ lesions are low risk for subsequent subaortic obstruction because after repair the angle between the plane of the infundibular septum and the left $A V$ valve anulus is nearly normal (Fig. 7). Increasing the outflow angle in those patients with AVSDs and subaortic stenosis toward normal may decrease the
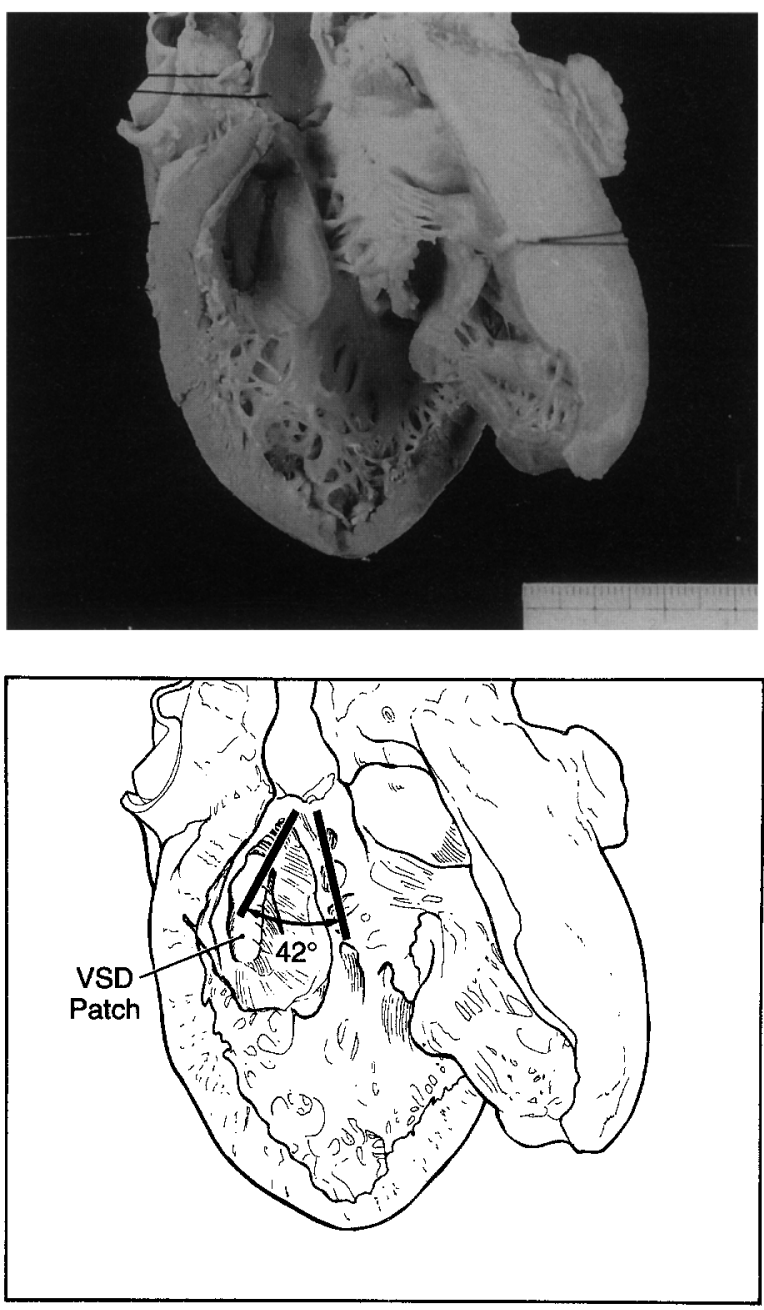

Fig. 6. Creation of an infundibular VSD with a patch from the right ventricular side widens the outflow angle but does not alter the inlet anatomy. This leaves a long LVOT.

likelihood of recurrence by lessening elongation and narrowing of the LVOT. Length of follow-up in the 3 patients from the report treated by either patch enlargement of the LVOT or leaflet augmentation was insufficient to reach a definitive conclusion about recurrence of subaortic stenosis.

DeLeon and colleagues ${ }^{1}$ reported on 12 patients with subaortic stenosis associated with AVSD. Obstruction was caused by fibromuscular tissue in 7 , mitral valve abnormalities in 3, and tunnel stenosis in 2. Seven were treated by muscular resection, 2 by apicoaortic conduit, 2 by creation of an infundibular VSD and patching, and 1 by lifting the malattached mitral valve from the LVOT and augmenting the leaflet. There was 1 late death from graft sepsis in a 


\section{Van Arsdell et al.}
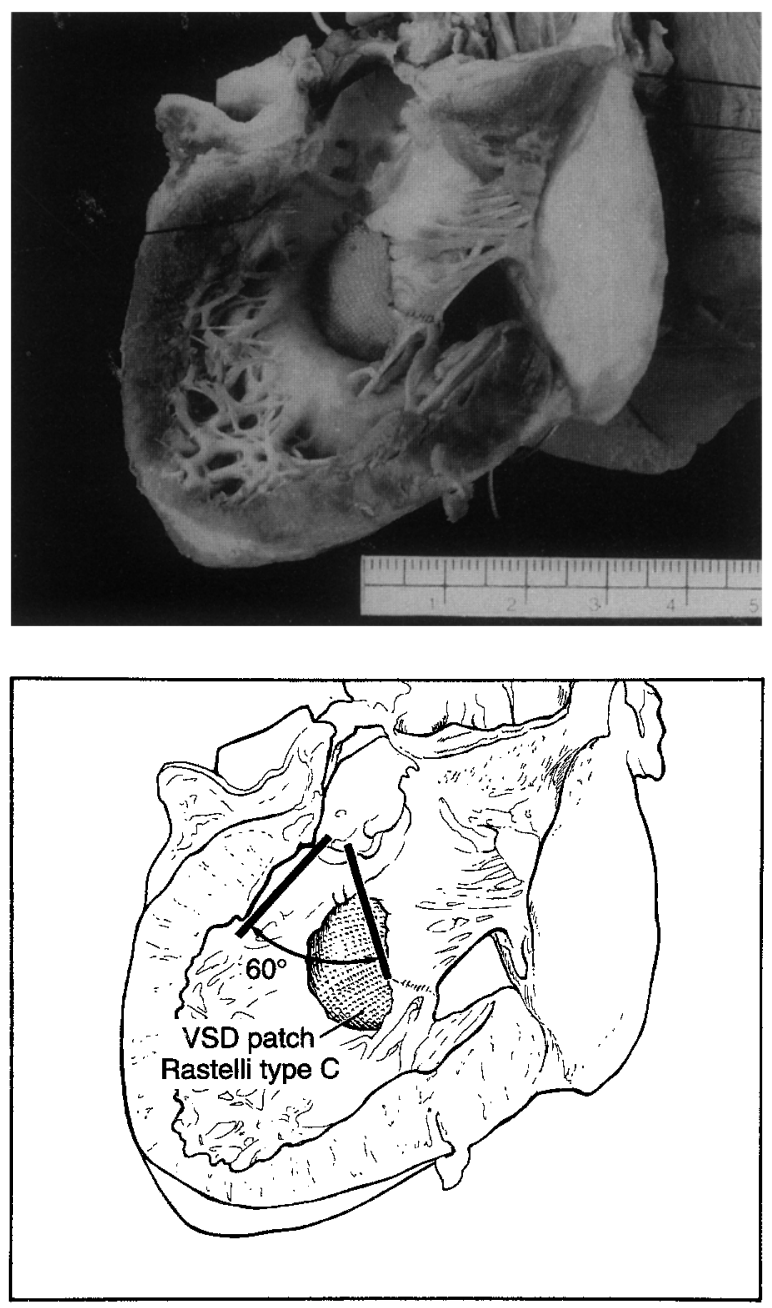

Fig. 7. The outflow angle is wide in Rastelli type C lesions, which may explain the low incidence of subaortic stenosis.

patient treated with an apicoaortic conduit. Mean follow-up was 5 years. No recurrence of subaortic stenosis was reported. Because of the inevitable need for conduit replacement, we agree with these authors that treatment other than an apicoaortic conduit is preferable.

Previous reports have indicated that Down syndrome is not prevalent in those patients having subaortic stenosis. ${ }^{14,24}$ In this report $47 \%(9 / 19)$ of the patients had trisomy 21. Manning and associates ${ }^{14}$ found that left-sided obstructive lesions were more prevalent in patients with septum primum defects necessitating repair within the first year of life. Three patients in our series were infants with coarctation, of whom 2 had transitional defects and 1 a septum primum defect. The 3 patients who had
The Journal of Thoracic and

Cardiovascular Surgery

November 1995

subaortic stenosis at the time of initial AVSD repair were 3 to 8 years of age. Two of these children had septum primum defects and 1 had a transitional defect. Reeder and colleagues ${ }^{2}$ performed Doppler and echocardiographic analysis of fixed subaortic stenosis in AVSD. As in this report, they observed that the stenosis could be acquired, progressive, and recurrent.

Because of the potential for multiple causes of obstruction, a tailored operation may be necessary. Augmentation of the superior bridging leaflet and myectomy are most likely sufficient except in those with a deviated outlet septum or thin outlet septum that prevents significant myectomy. Creation of an infundibular VSD with subsequent patching may be required as well in these patients. A modified Konno operation without leaflet augmentation may be an option in patients having obstruction caused primarily by a deviated outlet septum; however, this does not enlarge the outlet angle as much as in combination with leaflet augmentation. Those patients having critical left AV valve support structures causing hemodynamic obstruction may require valve replacement with a low-profile valve and fibromyectomy or other outletenlarging procedures. Converting a Rastelli type A lesion to a type $\mathrm{C}$ lesion is an attractive option, but care must be taken not to alter the plane of leaflet coaptation. In this series repair was successfully achieved without aortoventriculoplasty.

This article was prepared with the assistance of the Editorial Services, The Hospital for Sick Children, Toronto, Ontario, Canada.

\section{REFERENCES}

1. DeLeon SY, Ilbawi MN, Wilson WR Jr, et al. Surgical options in subaortic stenosis associated with endocardial cushion defects. Ann Thorac Surg 1991;52:107683.

2. Reeder GS, Danielson GK, Seward JB, Driscoll DJ, Tajik AJ. Fixed subaortic stenosis in atrioventricular canal defect: a Doppler echocardiographic study. J Am Coll Cardiol 1992;20:386-94.

3. Piccoli GP, Ho SY, Wilkinson JL, Macartney FJ, Gerlis LM, Anderson RH. Left-sided obstructive lesions in atrioventricular septal defect. J THORAC CARDIOvASC SuRg 1982;83:453-60.

4. Ceithaml EL, Midgley FM, Perry LW. Long-term results after surgical repair of incomplete endocardial cushion defects. Ann Thorac Surg 1989;48:413-6.

5. Gow RM, Freedom RM, Williams WG, Trusler GA, Rowe RD. Coarctation of the aorta or subaortic stenosis with atrioventricular septal defect. Am J Cardiol 1984;53:1421-8. 
6. Ebels T, Ho SY, Anderson RH, Meijboom EJ, Eijgelaar A. The surgical anatomy of the left ventricular outflow tract in atrioventricular septal defect. Ann Thorac Surg 1986;41:483-8.

7. Starr A, Hovaguimian H. Surgical repair of subaortic stenosis in atrioventricular canal defects. J THORAC Cardiovasc Surg 1994;108:373-6.

8. Lappen RS, Muster AJ, Idriss FS, et al. Masked subaortic stenosis in ostium primum atrial septal defect: recognition and treatment. Am J Cardiol 1983;52:336-40.

9. Kirklin JW, Barratt-Boyes BG. Congenital aortic stenosis. In: Kirklin JW, Barratt-Boyes BG, eds. Cardiac surgery. New York: Wiley, 1986:971-1012.

10. Cole BR. Blossom statistical package for Lotus 1-2-3. Data Management Branch, Bethesda, Maryland: National Institutes of Health. Release 2, March 1987.

11. Sellerș RD, Lillehei CW, Edwards JE. Subaortic stenosis caused by anomalies of the atrioventricular valves. J THORAC CARDIOVASC SURG 1964;48:289-302.

12. Draulạs-Noe HAY, Wenink ACG. Anterolateral muscle bundle of the left ventricle in atrioventricular septal defect: left ventricular outflow tract and subaortic stenosis. Pediatr Cardiol 1991;12:83-8.

13. Taylor NC, Somerville J. Fixed subaortic stenosis after repair of ostium primum defects. Br Heart $\mathrm{J}$ 1981;45:689-97.

14. Manning PB, Mayer JE, Sanders SP, et al. Unique features and prognosis of primum ASD presenting in the fitst year of life. Circulation 1994;90(Suppl): II30-5:

15. Ebels T, Meijboom EJ, Anderson RH, et al. Anatomic and functional "obstruction" of the outflow tract in atrioventricular septal defects with separate valve orifices ("ostium primum atrial septal defect"): an echocardiographic study. Am J Cardiol 1984;54: 843-7.

16. Spano PK, Fiddler GI, Mair DD, McGoon DC. Repair of atrioventricular canal associated with membranous subaortic stenosis. Mayo Clin Proc 1977;52: $121-4$.

17. Molthan ME, Paul MH, Lev M. Common A-V orifice with pulmonary valvular and hypertrophic subaortic stenosis. Am J Cardiol 1962;10:291-7.

18. Frommelt MA, Snider AR, Bove EL, Lupinetti FM. Echocardiographic assessment of subvalvular aortic stenosis before and after operation. J Am Coll Cardiol 1992;19:1018-23.

19. Coleman DM, Smallhorn JF, McCrindle BW, Williams WG, Freedom RM. Postoperative follow-up of fibromuscular subaortic stenosis. J Am Coll Cardiol 1994;24:1558-64.

20. Jue KL, Edwards JE. Anomalous attachment of mitral valve causing subaortic atresia: observations in a case with other cardiac anomalies and multiple spleens. Circulation 1967;35:928-32.
21. Gewillig M, Daenen W, Dumoulin M, Van Der Hauwaert L. Rheologic genesis of discrete subvalvular aortic stenosis: a Doppler echocardiographic study. J Am Coll Cardiol 1992;19:818-24.

22. Rosenquist GC, Clark EB, McAllister HA, Bharati S, Edwards JE. Increased mitral-aortic separation in discrete subaortic stenosis. Circulation 1979;60:70-4.

23. Chang C-I, Becker AE. Surgical anatomy of left ventricular outflow tract obstruction in complete atrioventricular septal defect. J THORAC CARdiovasC Surg 1987;94:897-903.

24. De Biase L, Di Ciommo V, Ballerini L, Bevilacqua M, Marcelletti C, Marino B. Prevalence of left-sided obstructive lesions in patients with atrioventricular canal without Down's syndrome. J THORAC CARDIOVASC SURG 1986;91:467-72.

\section{Discussion}

Dr. Albert Starr (Portland, Ore.). Dr. Van Arsdell and associates have presented a 12-year experience with 27 operations on 19 patients for AV canal with subaortic stenosis, with an actuarial recurrence rate of more than $80 \%$ after additional fibromuscular removal. That is important information. They further pointed out the complexities with the morbid anatomy, with the fibromuscular and mitral valvular components. They stressed the importance of the abnormally small angle between the plane of the outlet septum and the septal crest, which provides a substrate for recurrent stenosis, despite myectomy or a modified Konno procedure.

They also emphasize the rarity of subaortic stenosis after type C AV canal repair. That provides some insight into the possible mechanisms for recurrence, because the recurrence rate is higher in type $A$ with shortened chordae or type A with restricted VSD or ostium primum atrial septal defect. This mirrors our own experience with complete AV canal repair and suggests that the abnormality of the septum is a possible cause for the recurrences.

[Slide] The septal crest has a "scooped-out" appearance with a type C VSD. The leaflets are then hung up on the patch at a high level and, if all the chordae are removed from the underside of the leaflet to the septum, the valve no longer has any function in providing a subaortic stenosis; however, in the presence of an ostium primum atrial septal defect, or when the defect is restricted, then the mitral valve is tethered to a shortened septum. We believe that it is this that provides the enhanced risk of recurrent obstruction.

[Slide] Instead of measuring the angle, as the current authors have done, we have measured the length of the outflow septum and the inflow septum. Normally these are about the same size and can be easily measured by echocardiography. In partial AV canal there may be an enormous difference between the size of the inlet septum and the size of the outlet septum. If we hang the mitral leaflet up then, if we divide the mitral leaflet from the crest of the septum and insert a patch, then this normal length of the septum is restored.

[Slide] I would like to describe the operative approach 


\section{Van Arsdell et al.}

The Journal of Thoracic and

Cardiovascular Surgery

November 1995

that we have used in 3 patients: The leaflet is mobilized, chordae attached from the underside to the septum are divided, and then a patch of glutaraldehyde-preserved pericardium is inserted. We have had a perfect result in 2 of the 3 patients on whom we have operated thus far. These 2 patients had ostium primum. One was operated on at 6 months of age and at about 3 years of age. Gradients were present at the time of the primary operation in both patients. We have performed one operation in which the gradient was alleviated below the valve. However, because of hypoplasia of the aortic annulus, the patient still has rather high flow velocities in the aortic root and will probably require some kind of valve replacement in the future, although the patient is doing clinically well.

By examining this broad spectrum of pathologic conditions and by taking note of the abnormal substrate left behind after correction of some of these AV canal problems, as the author has shown, we may have some very good insight into how to avoid recurrences in the future.

Dr. Van Arsdell. Converting a Rastelli type A defect or a transitional defect to a Rastelli type $\mathrm{C}$ defect enlarges the outflow angle. Moving the leaffet away from the outlet septum and enlarging it effectively widens and shortens the LVOT. I believe this will lessen the incidence of recurrence, although we do not know how durable the repair will be. We hope it will be better than the results demonstrated in this report.

Dr. Florentino J. Vargas (Buenos Aires, Argentina). There is a group of patients who I believe deserve mention-the group with AV canal in whom Down syndrome is not present. Left-sided lesions tend to be more frequent in this group. Of a total of 100 patients with $\mathrm{AV}$ canal operated on at our Italian Hospital of Buenos Aires since 1988, we evaluated a group of 15 patients in whom Down syndrome was not present. Both left-sided obstructions and unfavorable inlet anatomy were more prevalent than in patients with associated Down's syndrome. When unfavorable inlet anatomy was present, such as double mitral orifice, parachute valves, or significant leaflet tissue deficiency, the incidence of late $A V$ valve replacement was surprisingly high. For all of them, any kind of leftsided obstruction was also common. Additionally, there is a potential combination of left-sided obstructions (already present) and the risk of acquired subaortic obstruction after an eventual posterior $\mathrm{AV}$ valve replacement.

We believe that this group of patients (common AV canal without Down syndrome) becomes differentiated into a more unfavorable category than patients with Down syndrome plus AV canal in terms of anatomic substrate and postoperative long-term results. Could you comment on our observations regarding the surgical outcome of this group of patients?

Dr. Van Arsdell. In our experience 9 of these children had Down syndrome, so I cannot say we only see this only in patients without Down syndrome. Others have reported an increased incidence of left-sided obstructive lesions in the non-Down setting. We did see other left-sided obstructive lesions; 3 of these patients had previously had coarctation repairs. 